\title{
Research Status of the Quaternary Sedimentation in the Chengdu Basin
}

\author{
Zhao Xueqin ${ }^{1}$, Zhao Lijuan ${ }^{2,}$, Wang Fudong ${ }^{1}$ \\ ${ }^{1}$ Institute of Environment and Resources, Southwest University of Science and Technology, Mianyang, China \\ ${ }^{2}$ School of Foreign Language and Cultures, Southwest University of Science and Technology, Mianyang, China

\section{Email Address:} \\ kristy_030827@163.com (Zhao Lijuan)
}

\section{To cite this article:}

Zhao Xueqin, Zhao Lijuan, Wang Fudong. Research Status of the Quaternary Sedimentation in the Chengdu Basin. Science Research. Vol. 3, No. 5, 2015, pp. 256-260. doi: 10.11648/j.sr.20150305.14

\begin{abstract}
The Quaternary of the Chengdu Basin contains abundant geological information. After being studied for decades, there are still some disputes over the Quaternary sedimentary environment and evolution and the filling sequence of basin, etc., on the whole even though some common perspectives have been reached with regard to stratigraphic architecture and structural characteristics. Particularly, more aspects must be further studied, including gravel characteristics and response to tectonic activity.
\end{abstract}

Keywords: The Chengdu Basin, Quaternary, Sedimentation, Gravel

\section{Introduction}

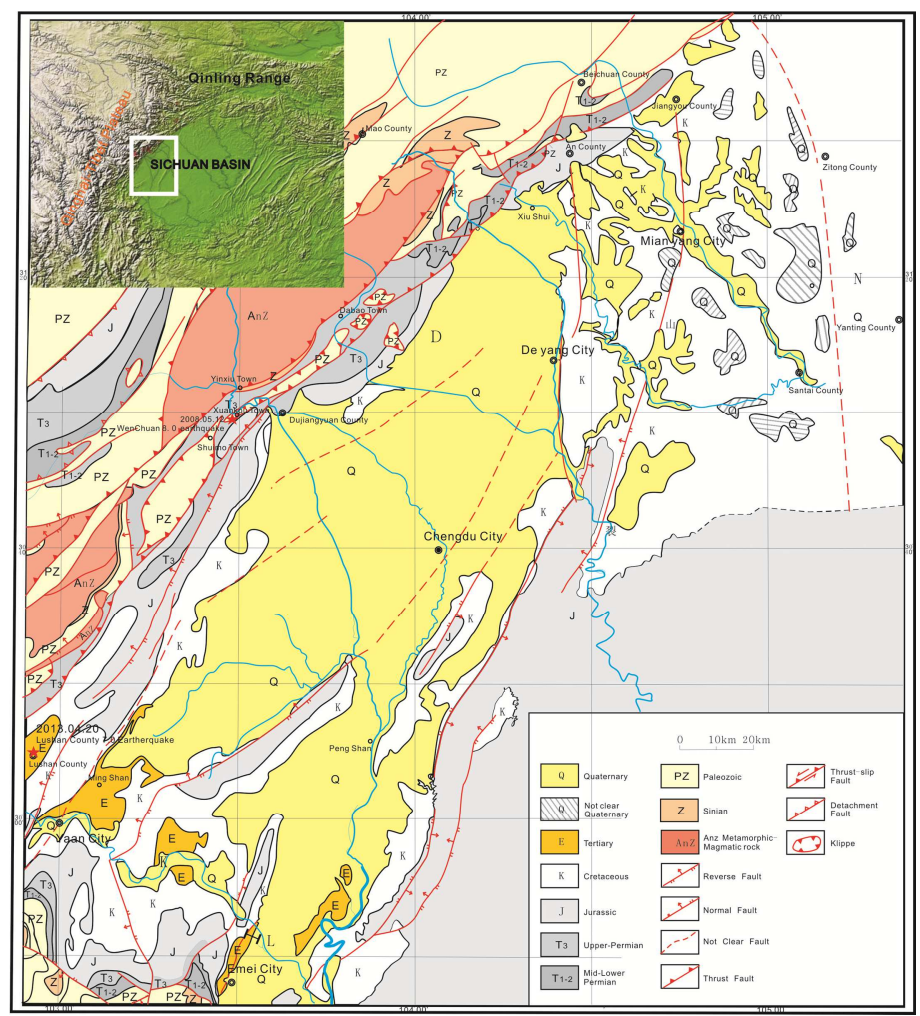

Figure 1. The geological map of Chengdu Basin. 
Situated in the west of the Sichuan Basin, the Chengdu Basin stands between Longmen Mountain and Longquan Mountain in the east-west direction and extends to Xiushui of Qi'an County in the north and the regions of Mingshan and Pengshan in the south (Figure 1). In the late Cenozoic era, the edge of the basin descended abruptly to form a highly thick layer of Quaternary sediments dominated by sedimentation of mountain-front molasse and sand-conglomerate (Liu, 1983), while Longmen Mountain was uplifted dramatically at the southeastern edge of the Qinghai-Tibet Plateau. The formation is not only attributed to climatic conditions and effect of water flow, but also restricted by the strength and pattern of tectonic movement, so it contains abundant information on tectonic movement and deformation. In addition to ideal geographic and tectonic conditions, the region is always one of the key regions in the study on the late Cenozoic deformation of plateau, the uplift of plateau and the paleogeographic and palaeoclimatic changes (Xu et al., 1997). Meanwhile, it is also crucial to the study on the changes of climate $\&$ water system and ecological environment in the upstream region of the Yangtze River (Liang et al. 2014).

\section{Formation of the Chengdu Basin}

The Chengdu Basin situates in the west of the Sichuan Basin. It stands between Longmen Mountain and Longquan Mountain in the east-west direction and extends to Xiushui of Qi'an County in the north and the regions of Mingshan and Pengshan in the south. A highly thick layer of Quaternary sediments dominated by sedimentation of mountain-front molasse and sand-conglomerate is formed within the basin (Fig. 1). According to 1:200,000 geological map (1980), the sediments are divided into middle and lower Pleistocene Dayi conglomerate and Yaan conglomerate, upper Pleistocene Guanghan strata (Jiangbei gravel bed) and Chengdu clay and Holocene.

With regard to the formation of the Chengdu Plain (Basin), there are different views of point. Li et al., (1964) put forward for the first time that the Chengdu Plain was a Cenozoic tectonic basin, and named it the Chengdu Depression with the Quaternary sedimentation of more than $300 \mathrm{~m}$. He (1987) argued that it was a compression-torsion downfaulted basin of the Quaternary downfault. (Xu and Liu, 1982) believed that the ramp of north-east Longmen Mountain fault and Longquan Mountain fault at the end of the Tertiary period gave birth to the Chengdu Basin, and the ramp was further developed in the middle and late Quaternary period to make hills on both sides of the basin rise continuously and deepen the central depression of the basin. Xu et al. (1997)claimed that, in the Quaternary period, the north-east Quaternary fault developed in the west of Longquan Mountain inside the Sichuan Basin, and the Quaternary downfaulted basin (the Chengdu Basin) was formed. There was a static tectonic period between the Miocene epoch and the Pliocene epoch, and the Chengdu Basin was a new basin overlapping high planation surface. After studying the shape and structure of the basin and its relations with Longmen Mountain fault zone, they believed that the Chengdu Basin was not the fore-land basin of Longmen Mountain tectonic belt anymore, and objected that Dayi conglomerate would be regarded as the early Pleistocene molasse structure at the eastern edge of the Qinghai-Tibet Plateau. Li et al. (2011) pointed out that in the Early Jurassic, the current Sichuan Basin was still developing as fore-land basin, which developed into the belt within the front range of Longmen Mountain in the Cretaceous period, gradually disappeared in the Tertiary and Quaternary periods, and ended in the current architecture.

Zeng and Li (1994) thought that the unconformable contact between the Quaternary and underlying formation represented the fifth large-scale reverse thrust activity of Longmen Mountain fault since the Mesozoic era. The structure and shape of the Chengdu Basin were mainly subject to Longmen Mountain thrust belt in the west, and Longquan Mountain fore-land uplift and basal major fault in the east. The sedimentation of the basin was the response of Longmen Mountain thrust belt to the Quaternary reverse thrust-nappe effect, so they showed clear connection and consistence. On this basis, they brought forth the sedimentation response model for Longmen Mountain thrust belt against the reverse thrust-nappe effect. Li et al (2002) utilized the landform features and characteristics of Longmen Mountain active tectonics, the Quaternary filling characteristics of the Chengdu Basin and the study on tectonic pattern of the basin, and put forth that the present Longmen Mountain and its fore-edge basin were mainly the products of strike-slip effect and erosional unloading effect. They believed that the Chengdu Basin was a strike-slip extrusion basin under the joint effect of strike-slip and reverse thrust of Longmen Mountain orogenic belt in the late Cenozoic era.

\section{Studies of the Quaternary Formation in the Basin}

The Quaternary formation in the basin is dominated by terrigenous clast accumulation and mainly consists of sediments in the alluvial fans and frontal alluvial plain created by the crosswise rivers that traversed Longmen Mountain. Its extension is constrained by two water systems, i.e. Minjiang River and Tuojiang River. Zeng and Li (1994) believed that the Quaternary sediments of the Chengdu Basin vertically formed the retrograding tectonic sequence, which was composed of 3 fining-upward retrograding sequences, and were accompanied by the cyclical appearance of coarse wedge-shaped clastics featuring conglomerate or gravel bed. On this basis, Li et al (2002) divided the evolution of the Quaternary Chengdu Basin into three phases, and claimed that the reverse thrust activity of Longmen Mountain controlled the formation of basin in the first and second phases, while the strike-slip activity limited the formation of basin in the third phase.

In the 1930s, Hthorp et al. (1936) brought forward the ideas 
of the Quaternary glaciers and clay aeolian formation of the Chengdu Plain. In 1978, Li et al. (1984) divided the Western Sichuan Plain into 5 glacial epochs and identified the sequence of the basin's sediments overlying Dayi conglomerate. Li et al. (1980) discovered 3 completely different sporo-pollen assemblages formed in the early, middle and late Pleistocene epochs in the Quaternary formation of the Chengdu Plain. Later on, Liu (1983), Xu et al. (1982), Zeng et al. (1994), Zhang et al. (2000) and Li et al. (2002) carried out the systematic and careful studies on the Quaternary formation of the Chengdu Plain and Basin. Gradually, two views appeared with regard to the origin of the Quaternary gravel: glaciers and alluvium.

Li et al. (1964) classified Dayi conglomerate into the Quaternary early Pleistocene, but Liu (1983) believed that it appeared in the Miocene epoch based on the comparison with regional strata. Based on ESR dating, Li et al. (2001) argued that the sedimentation of Dayi conglomerate started in 2.6 2.4 Ma. Li et al. (2006) performed the ESR dating for the lower sandstones on the profile of Dayi conglomerate, indicating that Dayi conglomerate was formed between 0.82 3.6Ma. Moreover, they carried out the ESR dating for 4 sand layers in Yaan gravel bed and obtained the ages of $0.20 \mathrm{Ma}, 0.35 \mathrm{Ma}$, $0.46 \mathrm{Ma}$ and $0.64 \mathrm{Ma}$ respectively, so Yaan gravel bed was formed between $0.20 \sim 0.64 \mathrm{Ma}$, which was around the middle Pleistocene period.

\section{Origin of Clay}

Zhou (1986) believed that the clay of the Chengdu Plain was carried by the floating ices, so it must be dated to the Quaternary early Pleistocene period. Chen et al. (1990) concluded that Guanghan clay and Chengdu clay belonged to the upper Pleistocene period based on the analysis of $\mathrm{C}$ ages and sporo-pollen, clay mineral, grain size and other data. Guanghan clay was formed 25,000 500,000 years ago, so it belonged to the river-lake sediments in the middle and late stages of the late Quaternary period. Chengdu clay was formed 10,000 25,000 years ago, so it was the aeolian sedimentation at the end of the late Pleistocene period. Qiao et al. (2007) and Yang et al. (2010) studied the magnetic stratigraphic, sedimentologic and geochemical properties of two profile systems in Shengli and Huangjia of Shuangliu County, Chengdu, and discovered that the red earth accumulation in the region was formed in the middle of the Quaternary period, and the mother substances for clay and patterned red earth in Chengdu might be aeolian. Moreover, they pointed out that the climatic characteristics of relative coldness-coolness in the Chengdu Plain in the middle of the Quaternary period were the regional response to the global climatic changes, while the quick uplift of the Qinghai-Tibet Plateau and the expansion of the glaciers might be the direct causes for the lower temperature in the region. And Yang et al. (2010) conducted the dating for clay on the profile of Anchang River, indicating that the sedimentation started in 528ka B.P, and argued that the widely distributed loess bed in the Chengdu Plain must be an embodiment of quick uplift in the
Qinghai-Tibet Plateau. On the basis of predecessors' research, Feng et al. (2014) systematically discussed the origin, provenance, age and climatic links of the Chengdu Clay.

\section{Tectonic Response of the Quaternary Gravel}

As an important component of sedimentary rocks, gravel has its special significance to the evolution of the basin and its formation is closely connected to crustal activity. The gravel bed in fore-land basin can be even regarded as the sign to indicate when uplift starts or becomes stronger in the plain. The study of gravel can help identify the position, lithology, exposure and climatic condition of source and the tectonic activity in the source area, and delve into the uplifting process of neighboring mountains and the activity history of major faults.

The gravel bed of the Chengdu Plain is of great significance to the study of the Quaternary formation, basin evolution, neotectonic movement and paleo-environment, etc. Especially, the tectonic significance revealed by the gravel bed has attracted much attention. Li et al. (2006) studied the typical Quaternary gravel sedimentary profile in the west of the basin, put forward the sedimentation response model for Longmen Mountain thrust belt against the reverse thrust-nappe effect, and claimed that the Chengdu Basin was a strike-slip extrusion basin under the joint effect of strike-slip and reverse thrust of Longmen Mountain orogenic belt in the late Cenozoic era. In addition, they divided the evolution of the Quaternary Chengdu Basin into three phases, and believed that the reverse thrust activity of Longmen Mountain controlled the formation of basin in the first and second phases, while the strike-slip activity limited the formation of basin in the third phase. Cui et al. (2009) studied 6 gravel beds in Pleistocene profile of Yaan and other regions, and concluded that all 4 Pleistocene gravel beds were composed of clastic sediments in the fore-land basin from ancient Qingyi River as it was affected by the nappe tectonics of Longmen Mountain between the late Pliocene epoch and the late Pleistocene epoch.

Through the study on the Neogene conglomerate in Yutang Town, which is the middle section of Longmen Mountain tectonic belt, He et al. (2011) argued that it reflected the increasingly intense Neogene crustal movement in the region of Longmen Mountain, and the transfer from NWW to NW occurred in the direction of paleotectonic stress field. Due to exposure conditions, the predecessors focused more on the west and southwest of the basin or centered on the detached exposed profile in their studies, but conducted little systematic research on the overall information of gravel bed. Moreover, they kept different views about sedimentation sequence, cause and formation environment, etc.

\section{New Research Trends}

Different scholars have put forth different models for the characteristics of late Cenozoic activity in the region (the 
eastern edge of the Qinghai-Tibet Plateau). Among them, the representative models include eastward escape model, right shear model and recently introduced lower crustal flow model. All these varying models have laid a theoretical foundation for our understanding about the tectonic activity in the region. Through all kinds of geological, landform, geophysical exploration and simulation techniques, the predecessors have thoroughly studied the times and characteristics of late Cenozoic Longmen Mountain fault belt activity, and accomplished a large number of research achievements. In addition, the Quaternary sedimentation of the Chengdu Basin has got more and more attention as it is taken as an important way to the study on the late Cenozoic tectonic activity of Longmen Mountain fault (Wang et al., 2013; Liang et al., 2014; Liu et al., 2015).

In recent years, a lot of researchers (Li et al.,2002; 2006; Cui et al.,2009; He et al.,2011) have started paying attention to the tectonic significance represented by the Quaternary. Through the study on the Quaternary development characteristics of the Chengdu Basin and the inversion analysis on the history of the Quaternary Longmen Mountain tectonic activity, discussion has been further expanded to cover the impacts of the Quaternary uplift of the Qinghai-Tibet Plateau and the tectonic movement of Longmen Mountain fault on the Quaternary sedimentation process of the Chengdu Basin. After conducting the related research, we believe that this will help reveal the intrinsic law of the Quaternary geological environment evolution in the basin, and provide the scientific basis for the decisions regarding the disaster control and environmental recovery of the Chengdu Plain.

\section{Conclusion}

Based on the research for decades, the relatively integrated stratigraphic system has been established for the Quaternary of the basin. However, there are still few researches on the sedimentary environment and evolution of the Quaternary, the filling sequence of the basin and the coupling with the process of Longmen Mountain orogenesis. Especially, further study should be carried out with regard to the relations between the tectonic deformation at the eastern edge of the Qinghai-Tibet Plateau and the formational evolution of the Chengdu Basin since the Quaternary, as well as the impacts of plateau uplift on the paleogeographic, palaeoclimatic and living environment for human beings.

\section{References}

[1] Chen Zhirong, He Yinwu, 1990. A preliminary discussion on date determination of Guanghan clay and Chengdu clay with $\sim(14)$ C dates. Journal of Mountain Science, No.3, pp.167-173.

[2] Cui Zhiqiang, Liu Dengzhong, Meng Qingmin, 2009.The origin of the Pleistocene gravel in western Sichuan depression. Geology of Chian, No.5, pp. 1065-1078.

[3] Feng Jinliang, Zhao Zhenhong, Zhao Xiang et al., 2014. The Origin, Provenance, Age and Climatic Links of the Chengdu
Clay: A Review. Journal of Mountain Science, Vol.32, No.55, pp.513-525

[4] He Chengguang, Shao Zhaogang, Qian Cheng et al., 2011. Gravel fabric characteristics of Neogene conglomerate layers in the middle sector of the Longmenshan structural belt and its tectonic significance. Geology in China, No.6, pp. 1467-1476.

[5] He Yinwu, 1987. On the formation of the Chengdu Basin (Plain). Regional Geology of China. No.2. pp. 169-176.

[6] Li Chengsan, Wu Yansheng and Li Yongzhao, 1964. A Collection of Research Papers on the Remains of Quaternary Glaciers in China: The Remains of Quaternary Glaciers at the Eastern Slope of the South Section and Front of Longmen Mountain in Sichuan. Science Press, Beijing.

[7] Li Daijun, 1980. Pleistocene Palynological assemblages in the Chengdu Plain. Acta Geological Sichuan, pp. 89-106

[8] Li J, Xie S, Kuang M, 2001. Geomorphic evolution of the Yangtze Gorges and the time of their formation. Geomorphology, Vol.41, no.2-3, pp.125-135.

[9] Li Yong, Hou Zhongjian, Si Guangyin et al., 2002. Cenozoic Tectonic sequence and tectonic events at the eastern margin of the Qinghai-Tibet plateau. Geology of China, Vol.29, No.1, pp.30-36.

[10] Li Yong, Li Bing, Steffen D et al., 2006. Provenance Analysis and Drainage Evolution in Late Cenozoic Chengdu Basin on Eastern Margin of Tibetan Plateau. Acta Sedimentologica Sinica, No.3, pp. 309-320.

[11] Li Yong, Li Yongzhao and Zhou Rongjun et al., 2002. Discovery of Quaternary fossil ice wedges in the Chengdu Plain and its palaeoclimatic significance. Journal of Geomechanics. No.4, pp.341-346.

[12] Li Yong, Zhou Rongjun and Dersmore Alexander L. et al., 2006. Continental Dynamic Process and Geological Response at Eastern Edge of Qinghai-Tibet Plateau. Geological Publishing House, Beijing.

[13] Li YongZhao, Shao ZhiGang, Li Daijun, 1984. The Quaternary Ice Age in the northwest edge of Sichuan Basin. Geological Publishing House, Beijing.

[14] Li Zhongquan, Ying Danli, Li Hongkui et al., 2011. Evolution of the Western Sichuan Basin and Its superimposed characteristics, China. Acta Petrologica Sinica. No.8m pp.2362-2370.

[15] Liang Bin, Zhu Bin, Wang Quanwei, et al. 2014. Quaternary geologocal and environment of Chengdu Plain. Geological Publishing House, Beijing.

[16] Liang Bin,Wang Quanwei, Zhu Bing et al., 2013. Optically stimulated luminescence dating of the Chengdu clay in the west Sichuan basin. Quaternary Sciences, Vol.33, No.4, pp.823-828

[17] Liang Mingjian;Li Dahu;Guo Hongmei, et al., 2014. Quaternary Tectonic Deformation and Geomorphologic Response Characteristics in the Southern Margin of Chengdu Basin. China Earthquake Engineering Journal, Vol.36, No.1, pp.98-106

[18] Liu Shao, Zhang Shimin, Ding Rui, et al. 2015. Upper crustal folding of the 2013 Lushan earthquake area in southern Longmen Shan, China, insights from Late Quaternary fluvial terraces. Tectonophysics, No.639, pp.99-108. 
[19] Liu Xingshi, 1983. The Quaternary Period of Sichuan Basin. Sichuan Publishing House of Science \& Technology, Chengdu.

[20] Qiao Yansong, Zhao Zhizhong, Li Zengyue et al., 2007. Aeol ian origin of the red earth formation in the Chengdu plain. Quaternary Sciences, No.2, pp.286-294.

[21] Thorp J, Dye D S, 1936. The chengtu clays-deposits of possible loessial origin in western and Northwestern Szechuan basin. Bulletin of the Geological Society of China, Vol.15, No.2, pp.225-242.

[22] Wang Mingming Zhou Bengang Yang Xiaoping, et al., 2013. Characteristics of Late-Quaternary Activity and Seismic Risk of the Northeastern Section of the Longmenshan Fault Zone. Acta Geologica Sinica, Vol.87, No.6, pp.1674-1689

[23] Xu Xiaosong, Liu Baojun, Xu Qiang, et al., 1997. Analysis and Geodynamics of Great Basins in West China. Geological Publishing House, Beijing.
[24] Xu Zhonglu and Liu Yaping, 1982. A preliminary analysis of the development of the Western Sichuan Plain based on visual interpretation of landsat images. Geological Review, No.5, pp. 439-446.

[25] Yang S, Fang X, Shi Z, et al., 2010. Timing and provenance of loess in the Sichuan Basin, southwestern China. Palaeogeography, Palaeoclimatology, Palaeoecology, Vol.292, No.1-2, pp.144-154.

[26] Zeng Yunfu and Li Yong, 1994. On the sedimentary response to the effect of reverse thrust and nappe in Longmen Mountain-Taking the Chengdu Basin as an example. Mineralogy and Petrology, No.1, pp.58-66.

[27] Zhang Zhuoyuan, Chen Xulun and Liu Shiqing et al., 2000. Origin and geological age of the Danling-Simong gravel bed. Journal of Mountain Science. No.S1, pp.8-16.

[28] Zhou Xulun, 1986. The calcareous tuberculosis in Chengdu clay. Hydrogeology \& Engineering Geology, No.4, pp.29-31. 